\title{
Acoustical Observation with Multiple Wave Gliders for Internet of Underwater Things
}

\author{
Hualin Lan, Yunfei Lv, Jianjia Jin, Jianghui Li, Dajun Sun, and Zhiguo Yang
}

\begin{abstract}
One of the challenges of Internet of Underwater Things (IoUT) is the design of nodes for collecting information from underwater, with features of low cost, long-term, long range, voyage routing, and real-time communications. Wave glider, has shown great potential acting as IoUT nodes through its persistent, long range travelling, and flexibility underwater. In this paper, we propose an architecture of Internet of Underwater Things, involving multiple wave gliders as nodes for acoustical observation. We present target localisation method via acoustical observation of nodes with multiple wave gliders deployed underwater, by which precision of bearing estimation of each node is required to achieve high precision of localisation. With the data collected, we apply a compensation method of bearing estimate when the hydrophone array is rotating during the observation. The feasibility of acoustical observation of wave gliders has been validated through both simulation and sea trial data, which is of great potential to be nodes for constructing IoUT.
\end{abstract}

Index Terms-Smart Ocean, Acoustic Wave Glider, Bearing Estimate, Direction of Arrival Estimation.

\section{INTRODUCTION}

With the emergence and development of the concept of industry 4.0, Internet of things (IoT) [1]-[3] becomes the fundamental of 'Smart Cites' [2], as all the terrestrial objects are connected and information is shared [4]-[11]. Since 70 percent of the earth is covered with water, Internet of Underwater Things (IoUT) has a prosperous future and the 'Smart Oceans' [4], [12]-[19] is the direction. Challenges of IoUT have been shown in data acquisition, data transmission and data processing [20], wherein the first two terms are different from those of terrestrial IoT and have attracted more attention in the design of IoUT.

Physical layer underwater communications and localisation [21]-[23] and the concept of underwater sensor networks have been presented for decades [24], while most of them are limited to specific tasks in local area and are difficult to extend to other fields. Generally, there are a number of limitations in the development of IoT for smart Oceans, e.g. the difficulty in the acquisition of ocean information, reliable communication, controllable position and low cost, etc. These can be partially solved by using buoys, the Automatic Identification System (AIS) and ocean observation systems.

Hualin Lan, Yunfei Lv, Jianjia Jin, and Dajun Sun are with the Acoustic Science and Technology Laboratory and the College of Underwater Acoustic Engineering, Harbin Engineering University, Harbin, Heilongjiang, 150001, China. Emails: lanhualin@ hrbeu.edu.cn, lvyunfei@hrbeu.edu.cn, jinjianjia@163.com, and sundajunmail@163.com.

Jianghui Li is with the Institute of Sound and Vibration Research, University of Southampton, Southampton, SO17 1BJ, U.K. Email: J.Li@soton.ac.uk.

Zhiguo Yang is with the National Deep Sea Center, Qingdao, Shandong, 266237, China. Email: zg.yang@163.com.
A variety of buoys, for monitoring the climate change, have been deployed in the global ocean [25]-[27]. With these buoys, we are able to remotely monitor the ocean dynamics, e.g. collecting information of wind speed, wind direction, current, wave height, and wave direction, as well as forecasting the weather with the collected information from the observation [26]-[30], particularly for the warning of Tsunami. Special buoys such as ARGO Array [31] have been deployed across the global ocean with the support of more than 30 countries since 1990s in order to monitor the global climate change [26]. ARGO consists of 3,800 free-drifting profiling floats for the measurement of temperature, salinity and velocity of the upper 2,000 m depth of the ocean. All these data can be relayed and made publicly available within hours after collection. However, these ARGOs are freely drifted and the location of them are not controllable.

The AIS [32], usually compelled to be installed in vessels whose tonnage is large enough, is an identification system used for collision avoidance and localisation. Ship information, including its Maritime Mobile Service Identity (MMSI), name, length, width, draught, and speed are broadcasted via radio in messages. When the ships are off-shore, the emitted AIS messages can be received by other ships and terrestrial antennas, and finally reach clients through existing internet. Therefore, all of these ships can exchange information with each other. However, when a ship travels far from the continent, the information propagation in the channel may be unsuccessful. By using the satellite communications, AIS is extended to the application in the global ocean [33]. Furthermore, AIS itself can be part of an IoT for 'Smart Ocean' as it connects landbased humans and ocean-based ships. While the information from vessels is limited, the IoT increases the amount of information and can be applied to build 'Smart Ocean'.

In recent years, a few ocean observation networks [34][37] based on cable connection have been built. Examples include the Ocean Observatories Initiative (OOI) since 2006 by National Science Foundation of America, the Ocean Networks Canada (ONC) [38]-[42], the European Multidisciplinary Seafloor and Water-Column Observatory (EMSO), the Dense Oceanfloor Network System for Earthquakes and Tsunamis (DONET) and the S-net [43]. These Ocean Observation Systems collect underwater information and transmit it to the data processing centre via cables. These systems are used for long-term and continuous monitoring underwater acoustic data together with environment sensing data. While they possess stability but without flexibility, e.g. the difficulty and high cost to move them around.

Some wireless underwater acoustic networks such as the 
Persistent Littoral Undersea Surveillance Network (PLUSNet) [44]-[46] have also been built. In these systems, while links between underwater nodes and sea surface gateways can be appropriately built using RF or acoustics, it is hard to extend such links to the application in global ocean with persistent real-time monitoring, because of either limited energy or limited bandwidth of these systems.

Difficulties in data acquisition in the ocean lie in the data source diversity and environment complexity. Different data, such as wind, flow, depth, pressure and noise, are needed to explore the ocean and correspondingly different sensors should be used. Various platforms with specific features were designed for these sensors. For instance, a quiet platform is needed for an acoustic observation system. As the ocean environment varies spatially and temporally, robustness is crucial for platform design and adapting to different conditions. Longterm observation is another challenge as ocean environment is salty and humid, i.e. the material of the platform may suffer from corrosion and ageing over time. Furthermore, the cost is a practical barrier for the widespread use of expensive platform as too many nodes would be needed for covering a wide area of ocean.

Difficulties in data transmission in the ocean is another barrier in the construction of IoUT. Underwater acoustic communications, with the drawback of high latency and relative small bandwidth, is the only way for real-time data transmission if one observation node such as autonomous underwater vehicle (AUV) is used. Thus a platform which combines underwater observation and real-time transmission can be useful.

Wave glider [47]-[50] is a kind of wave propelled ocean vehicle which can fulfil persistent observation as the power can be supplied by solar panels. A competing instrument could be the AUV. However, its energy supplying system limits the long-term work of it underwater, and the network has to be rebuilt when its energy is exhausted. A wave glider installed associated with sensors such as hydrophones, compass, depth sensor, the ocean environment can be monitored [51]-[53]. As its power is supplied by solar panel, it can provide good performance for a long time. The network can be built since the data can be relayed by satellite. Of the most important, the cost of the Acoustic Wave Gliders (AWG) can be low, and it can be expended to the global ocean as station, whose course can be controlled [54].

The goal of this paper is to explore the observing ability of network consisting AWGs through underwater acoustic localisation. As demonstrated, subset of IoT for 'Smart Ocean' is built with three AWGs, which can detect and localise the sound wave radiated by the targets in the water. A special issue related to bearing estimation with a rotating acoustic unit in the water is discussed and a target localisation method is proposed.

This paper is organized as follows. In Section II an architecture of the IoUT with multiple AWGs is proposed. Then a compound compensation method for bearing estimate with rotated acoustic unit is discussed in Section III, followed by the target localisation using the bearing estimate of each AWG node in Section IV. The experiment results of AWG localisation in the sea are discussed in Section V. Finally, conclusion of IoUT with multiple AWGs and some discussions are given in Section VI.

\section{SYSTEM DESCRIPTION}

In this section, we describe an architecture of the IoUT with Multiple AWGs, to demonstrate its capability in the application in the global ocean and for the application of IoT in the 'Smart Ocean'.

\section{A. Architecture of the system}

As shown in Fig. 1, the IoUT consists of multiple AWGs acting as nodes, which are on the sea surface and moving forward with the wave, and a processing centre. The distance between any two AWGs varies from 2 to $10 \mathrm{~km}$, which is suitable for Very High Frequency (VHF) communication. The acoustic data collected from the acoustic unit towed by the wave glider is resampled and initially processed for each AWG node. Then the data are packaged and conveyed, via satellite data link, to the processing centre on shore, where data fusion is conducted [55]. Finally the information is dispatched to the user nodes. There are mainly two challenges to realise the IoUT. One is wireless communications, since there are few commercial satellites which are available to fulfil this task of data convey; the other is that the nodes can collect data correctly based at platforms with limited space. Therefore, compensation, particularly for the acoustic data, should be conducted (see Section III).

\section{B. AWG nodes}

As illustrated in Fig. 2, AWG node consists of a wave glider and a towed acoustic unit. The acoustic unit records underwater sound and extracts useful information. It requires a quiet, stable and balanced platform. However, when a wave glider moves forward along the planned course with a speed between $0.25 \mathrm{~m} / \mathrm{s}$ and $1 \mathrm{~m} / \mathrm{s}$, it also experiences upward and downward motion. Noise is produced from this motion and blades of the glider. A rubber cable is used to reduce the vibration and floats are used to keep equilibrium. Yet the acoustic unit still rotates with the effect from flow. Therefore, a compass is installed in the acoustic unit to monitor the rotation. Furthermore, two synchronized beacons are used to determine the precise position of hydrophone array. The position of the AWG is recorded with a GPS in real-time. There is also a solar panel implemented on the float to supply power for the system.

\section{Processing centre}

The processing centre is connected to the existing internet and process the data as required by the user. It is the role of a server and it is a challenge to deal with big data from different sources. Furthermore, the processing centre computes the optimum geometry for the distributed AWGs, and sends the instructions to them. AWGs can adjust their heading to satisfy the course requirements [54]. Geometry optimization would become more complicated when the number of AWGs increases. 


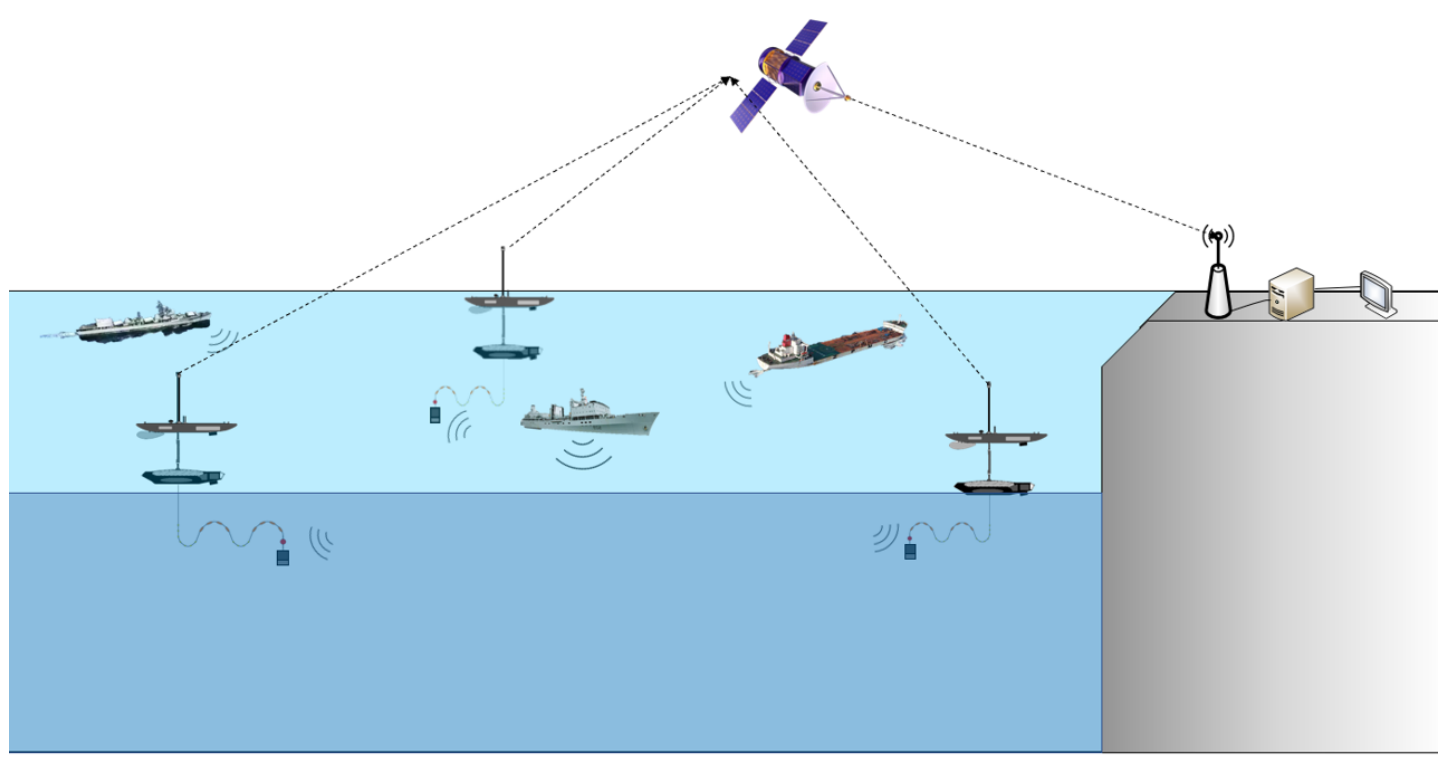

Fig. 1. Schematic of architecture of the IoUT with Acoustic Wave Glider (AWG). Wave gliders are the nodes of IoUT which collect information on the sea surface and underwater using different sensors. Specifically, a hydrophone array on each wave glider is used to record underwater sounds. The data collected by the wave glider is then conveyed to the data centre via relay nodes, e.g. satellites, etc. The collected information is extracted from data in the centre and then distributed to specific users.

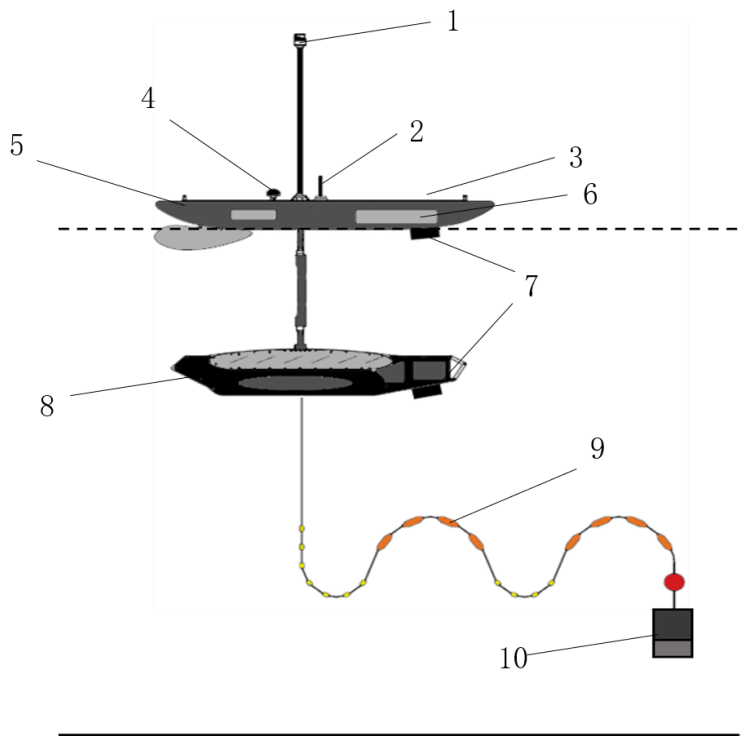

1-VHF antenna,

2-Satellite communication

antenna,

3-Solar panel,

4-GPS antenna,

5-Float,

6-Prcessor unit,

7-Beacon,

8-Glider,

9-Rubber cable,

10-Acoustic unit

Fig. 2. An Acoustic Wave Glider node. 1) Very High Frequency (VHF) is used for short range data communication. 2) Satellite communication antenna is used for long range data communication. 3) Solar panel is used to provide the electrical power needed by wave glider. 4) GPS antenna is used to receive the accurate real time position of wave glider. 5) Float is the main part of wave glider which keeps it from sunk. 6) Processor unit is to process the raw data preliminarily thus it suits for transmission with limited bandwidth. 7) Beacon is a sonar used to monitor the state of the towed hydrophone array. 8) Glider provides the power of motion of wave glider. 9) Rubber cable is used to isolate the towed hydrophone array from the vibration of main wave glider. 10) Acoustic Unit is the hydrophone array collecting the underwater acoustic information. 


\section{BEARING ESTIMATION AND TARGET LOCALISATION}

With the system mentioned above, the location of the target can be estimated using the bearings estimated from each node. In this section, a bearing estimation method with rotation compensation is given primarily, followed by the algorithm of localisation with bearing estimation.

\section{A. A compound compensation method for bearing estimation} with a rotated acoustic unit

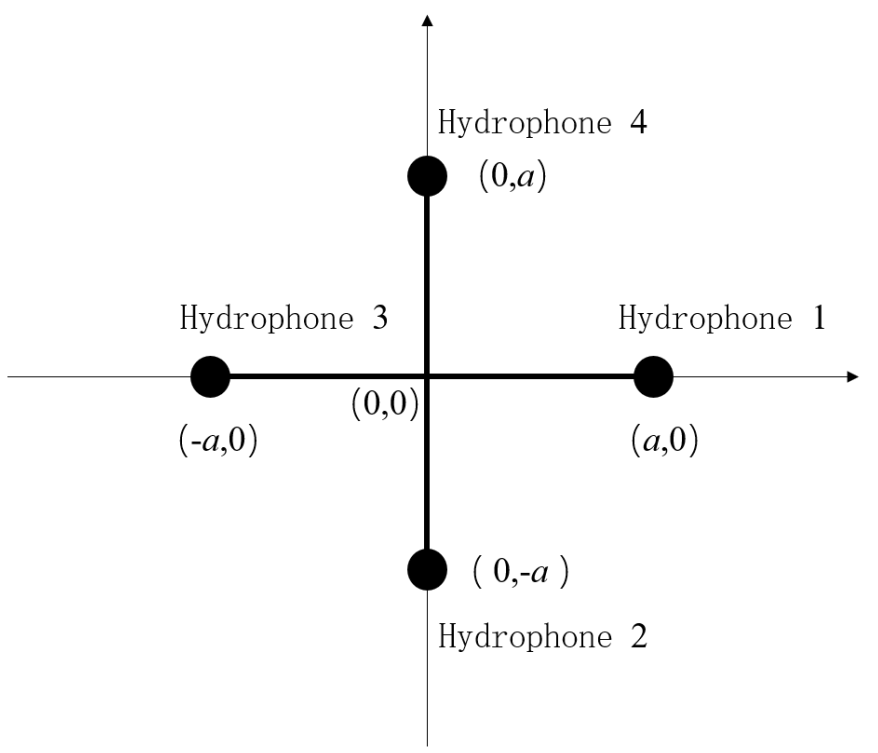

Fig. 3. The geometry of the hydrophone array. Four hydrophones are coplanar and located on two normal axis symmetrically with respect to the centre. Distance between two hydrophones on the same axis is $2 a$.

To estimate the direction of the target, a small hydrophone array is used to collect the acoustic data continuously. This is combined with a compass, which monitors the array rotation change simultaneously. The hydrophone array, as shown in Fig. 3, consists of four hydrophones on the vertex of a square whose diagonal length is $2 a$, and four hydrophones locate at $(a, 0),(0,-a),(-a, 0)$, and $(0, a)$. Since only relative direction of acoustic source can be estimated from hydrophone array, direction with respect to the north should be derived together with rotation data measured by the compass at the same time.

We assume the signal received by each hydrophone as:

$$
x_{i}(t)=s_{i}(t)+w_{i}(t), 0 \leq t \leq T,
$$

where $i=1,2,3,4$ indicates the order of hydrophones, and $0 \leq t \leq T$ is the time length of recorded signal, $s_{i}(t)$ is the signal received at the $i$ th hydrophone, and $w_{i}(t)$ is the noise received at the $i$ th hydrophone.

When the incident angle of the signal is $\alpha$ with respect to the hydrophone 1 in the array plane clockwise, assuming that there is no rotation, time delay between the hydrophone 1 and the hydrophone 3 is $\tau_{13}=2 a \cos \alpha$. Similarly, the time delay between the hydrophone 2 and the hydrophone 4 is $\tau_{24}=$ $2 a \sin \alpha$. Thus, the incident angle $\alpha$ can be easily estimated after the time delay $\tau_{13}$ and then the $\tau_{24}$ is estimated. The incident angle estimation is

$$
\widehat{\alpha}=\operatorname{Arg}\left(\widehat{\tau}_{13}+j \widehat{\tau}_{24}\right),
$$

where $j$ is the imaginary unit, and $\operatorname{Arg}(\cdot)$ is the argument of a complex number.

When the input signal occupies wideband in the frequency domain, $\widehat{\tau}_{13}$ can be calculated from the correlation of $s_{1}(t)$ and $s_{3}(t)$, and $\widehat{\tau}_{24}$ can be calculated from the correlation of $s_{2}(t)$ and $s_{4}(t)$, respectively. When the input signal is narrowband with a central frequency of $f_{0}, \widehat{\tau}_{13}$ and $\widehat{\tau}_{24}$ can be estimated from the corresponding phase difference $\varphi_{13}\left(f_{0}\right)$ between $s_{1}(t)$ and $s_{3}(t)$, and $\varphi_{24}\left(f_{0}\right)$ between $s_{2}(t)$ and $s_{4}(t)$, respectively, using the relationship:

$$
\widehat{\varphi}_{13}\left(f_{0}\right)=2 \pi f_{0} \widehat{\tau}_{13},
$$

and

$$
\widehat{\varphi}_{24}\left(f_{0}\right)=2 \pi f_{0} \widehat{\tau}_{24},
$$

where $\widehat{\varphi}_{13}\left(f_{0}\right)$ and $\widehat{\varphi}_{24}\left(f_{0}\right)$ can be estimated from cross spectrum method. Then (2) is updated as

$$
\widehat{\alpha}=\operatorname{Arg}\left(\widehat{\varphi}_{13}\left(f_{0}\right)+j \widehat{\varphi}_{24}\left(f_{0}\right)\right) .
$$

It is concluded that the performance of direction of arrival (DOA) can be improved with the increase of the integration time if the array keep stationary or the same heading during this period. However, the array in the sea water continuously rotates resulting from the flow movements. The performance is degraded since the correlation or cross spectrum cannot be summed coherently between segments and this rotation should be compensated, especially for weak signals, to keep a certain processing gain.

The proposed compound compensation method is in the frequency domain, dealing with the long integration time with rotation. The signals are divided into small segments and the cross spectrum is corrected to north reference and east reference for each segment firstly:

$$
P_{N}^{\prime m}(f)=P_{11}(f) e^{j\left(\widehat{\varphi}_{13}(f) \cos \theta_{c}(m)-\widehat{\varphi}_{24}(f) \sin \theta_{c}(m)\right)},
$$

and

$$
P_{E}^{\prime} m(f)=P_{11}(f) e^{j\left(\widehat{\varphi}_{24}(f) \cos \theta_{c}(m)+\widehat{\varphi}_{13}(f) \sin \theta_{c}(m)\right)},
$$

where $P_{N}^{\prime} m(f)$ is the cross spectrum of the $m$ th segment in the north reference, $P_{E}^{\prime} m(f)$ is the cross spectrum of the $m$ th segment in the east reference, $P_{11}(f)$ is the power spectrum of the $m$ th segment, and $\theta_{c}$ is the angle measured by the compass.

Then results of all the segments are summarized as

$$
P_{N}^{0}(f)=\sum_{m=1}^{M} P_{N}^{\prime m}(f),
$$

and

$$
P_{E}^{0}(f)=\sum_{m=0}^{M} P_{E}^{\prime} m(f),
$$

where $m=1,2 \ldots, M$, and $M$ is the number of segments. Finally, $\widehat{\alpha}(f)$ is estimated by

$$
\widehat{\alpha}(f)=\operatorname{Arg}\left\{\operatorname{Arg}\left[P_{N}^{0}(f)\right]+j \operatorname{Arg}\left[P_{E}^{0}(f)\right]\right\} .
$$


Note that in the direct compensation method the bearing estimation is derived by the summation of relative bearing estimate from (5) and the mean rotation data of the same period. When the rotation $\theta_{c}(m)$ is constant or the integration time, the two methods are consistent.

\section{B. Underwater acoustic localisation with multiple bearing estimate}

After the bearing of the targets is estimated from each node, the position can then be calculated incorporation with the position of corresponding nodes. Setting $N$ nodes whose positions are $\left(x_{i}, y_{i}\right), i=1,2 \ldots, N$ and the target locates at $\left(x_{s}, y_{s}\right)$, the DOA of the target with respect to each node is $\alpha_{i}, i=1,2 \ldots N$. We have

$\left[\begin{array}{cc}\sin \alpha_{1} & -\cos \alpha_{1} \\ \sin \alpha_{2} & -\cos \alpha_{2} \\ \vdots & \vdots \\ \sin \alpha_{N} & -\cos \alpha_{N}\end{array}\right]\left[\begin{array}{l}x_{s} \\ y_{s}\end{array}\right]=\left[\begin{array}{c}x_{1} \sin \alpha_{1}-y_{1} \cos \alpha_{1} \\ x_{2} \sin \alpha_{2}-y_{2} \cos \alpha_{2} \\ \vdots \\ x_{N} \sin \alpha_{N}-y_{N} \cos \alpha_{N}\end{array}\right]$.

Rewriting the equation, we have

$$
A X=B \text {, }
$$

where

$$
\begin{gathered}
A=\left[\begin{array}{cc}
\sin \alpha_{1} & -\cos \alpha_{1} \\
\sin \alpha_{2} & -\cos \alpha_{2} \\
\vdots & \vdots \\
\sin \alpha_{N} & -\cos \alpha_{N}
\end{array}\right], \\
B=\left[\begin{array}{c}
x_{1} \sin \alpha_{1}-y_{1} \cos \alpha_{1} \\
x_{2} \sin \alpha_{2}-y_{2} \cos \alpha_{2} \\
\vdots \\
x_{N} \sin \alpha_{N}-y_{N} \cos \alpha_{N}
\end{array}\right],
\end{gathered}
$$

and

$$
X=\left[\begin{array}{l}
x_{s} \\
y_{s}
\end{array}\right],
$$

By using the least square method, the position of the target $\left(x_{s}, y_{s}\right)$ can be estimated from the bearing estimates of all the nodes as

$$
X=\left(A^{T} A\right)^{-1} A^{T} B,
$$

where $\{\cdot\}^{T}$ denotes the matrix transpose.

\section{NUMERICAL SIMULATIONS}

In this section, we perform simulation to demonstrate the performance of bearing estimation of each node and target localisation with multiple AWGs.

\section{A. Bearing estimation}

An analysis without rotation is firstly given to indicate the necessity of compound compensation with compass data. Then, a simulation of bearing estimation with compound compensation is presented to show the effect of compensation.

Assume that a source in the far field radiates an acoustic signal at the central frequency of $300 \mathrm{~Hz}$. The signal and the noise are received by the hydrophones (see Fig. 3 ) of the acoustic unit. Then the bearing is estimated using (5) and (10). The signal-to-noise ratio (SNR) at $1 \mathrm{~Hz}$ bandwidth varies from
$-10 \mathrm{~dB}$ to $20 \mathrm{~dB}$ with the step of $2 \mathrm{~dB}$ and mean square error (MSE) of bearing estimates for 200 samples of the same SNR are calculated as

$$
\Delta \alpha=\sqrt{\frac{1}{N} \sum_{n=1}^{N}\left(\widehat{\alpha}_{n}-\alpha_{0}\right)^{2}},
$$

where $N=200$ is the estimation number of each SNR, $\widehat{\alpha}_{n}$ is the $n$th bearing estimate, and $\alpha_{0}$ is the true bearing of the target.

Simulation results shown in Fig. 4 (a) reveal the relationship between bearing estimation error and SNR under different integration times of $1 \mathrm{~s}, 5 \mathrm{~s}, 10 \mathrm{~s}, 30 \mathrm{~s}$, and $60 \mathrm{~s}$, where the frequency of signal is $300 \mathrm{~Hz}$. Generally, the bearing error becomes smaller as the SNR increases. Compare five results of different integration time, we find that the performance changes between $-5 \mathrm{~dB}$ and $10 \mathrm{~dB}$ when the integration time changes between $1 \mathrm{~s}$ and $60 \mathrm{~s}$. It is important to use relative longer integration time to obtain gain in SNR. However, direction measured by the compass changes during this longer integration time, which will deteriorate the estimates.

For complimentary, we also consider the relationship between bearing error and SNR at various frequencies of $100 \mathrm{~Hz}$, $200 \mathrm{~Hz}, 400 \mathrm{~Hz}$ and $800 \mathrm{~Hz}$, with the integration time of $10 \mathrm{~s}$. As shown in Fig. 4(b), the results with respect to the frequencies of $400 \mathrm{~Hz}$ and $800 \mathrm{~Hz}$ are acceptable, while its performance becomes worse for the frequencies of $100 \mathrm{~Hz}$ and $200 \mathrm{~Hz}$. This is because the length of the array is $0.45 \mathrm{~m}$, wavelengths corresponding to $100 \mathrm{~Hz}$ and $200 \mathrm{~Hz}$ are greater than those corresponding to $400 \mathrm{~Hz}$ and $800 \mathrm{~Hz}$.

To demonstrate the necessity of compound compensation of rotation in the bearing estimation, results of both direct compensation and compound compensation are simulated. A rotation of the hydrophone array is assumed as in Fig. 5(a), where the rotating period is $10 \mathrm{~s}$ and the rate of mean value is 1 degree per second. Two results are given in Fig. 5(b), compared with true bearing computed from GPS data. The integration time is $60 \mathrm{~s}$. From the figure, we can see that both estimates are fluctuated around the true bearing, however, the variation of the compound compensation method is much smaller.

\section{B. Target localisation}

The performance of target localisation is analysed and simulated in this section. Applying differential on (11), we obtain

$$
\begin{gathered}
{\left[\begin{array}{cc}
\sin \alpha_{1} & -\cos \alpha_{1} \\
\sin \alpha_{2} & -\cos \alpha_{2} \\
\vdots & \vdots \\
\sin \alpha_{N} & -\cos \alpha_{N}
\end{array}\right]\left[\begin{array}{c}
\Delta x \\
\Delta y
\end{array}\right]=} \\
{\left[\begin{array}{c}
{\left[\left(x_{s}-x_{1}\right) \cos \alpha_{1}+\left(y_{s}-y_{1}\right) \sin \alpha_{1}\right] \cdot \Delta \alpha_{1}} \\
{\left[\left(x_{s}-x_{2}\right) \cos \alpha_{2}+\left(y_{s}-y_{2}\right) \sin \alpha_{2}\right] \cdot \Delta \alpha_{2}} \\
\vdots \\
{\left[\left(x_{s}-x_{N}\right) \cos \alpha_{N}+\left(y_{s}-y_{N}\right) \sin \alpha_{N}\right] \cdot \Delta \alpha_{N}}
\end{array}\right]}
\end{gathered}
$$




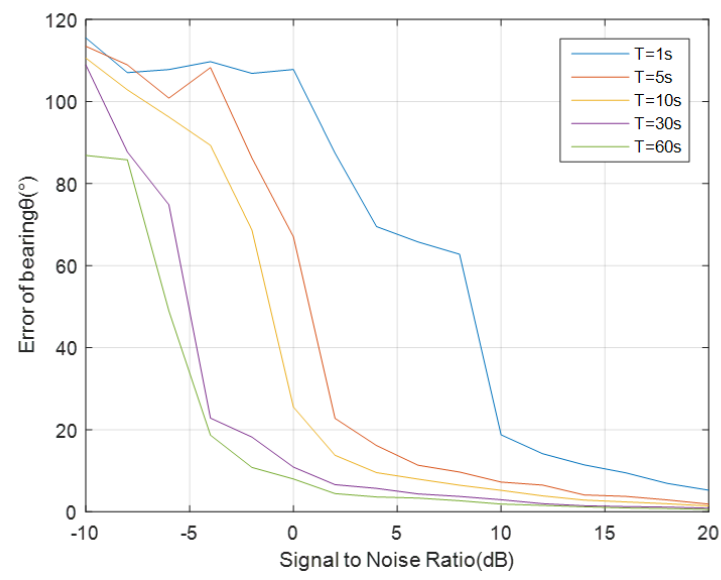

(a)

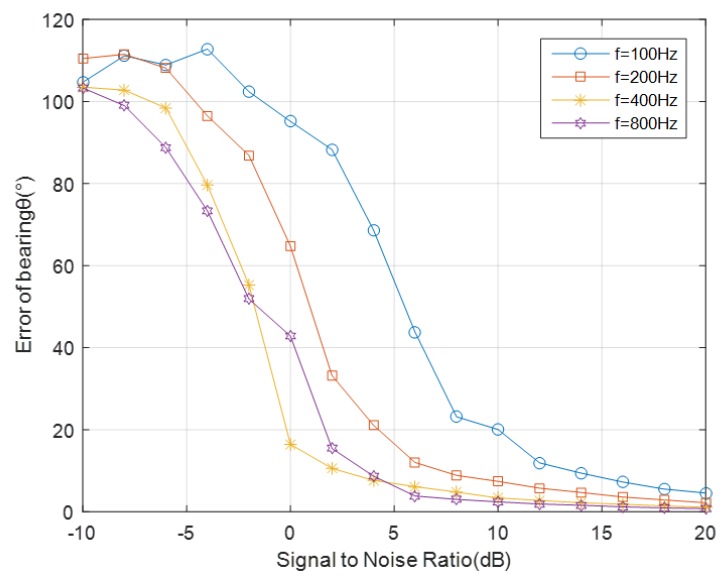

(b)

Fig. 4. Bearing estimation in the function of signal-to-noise ratio (SNR) at different conditions. (a) different integration time lengths; (b) different frequencies.

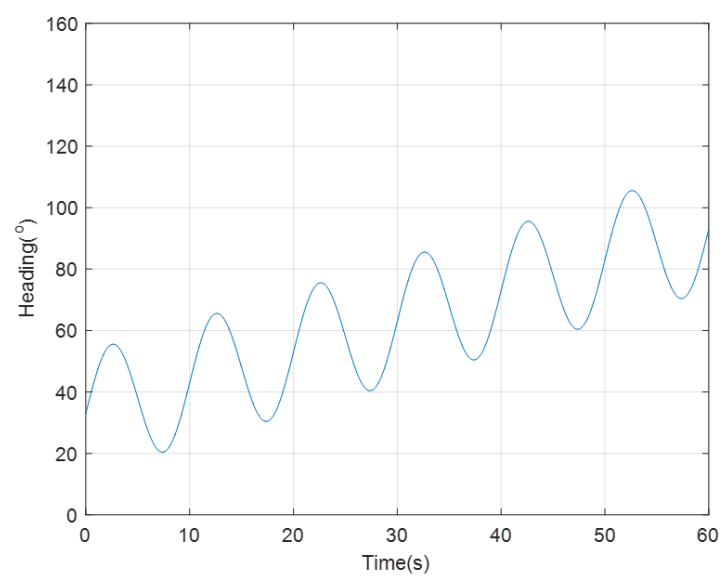

(a)

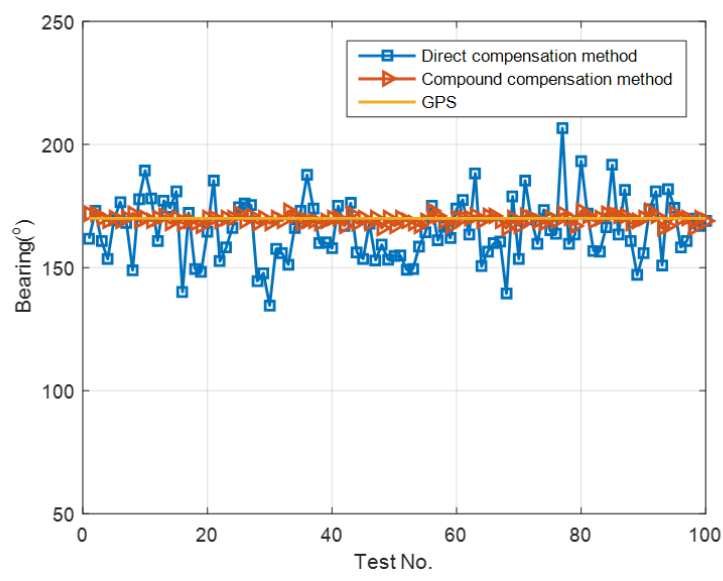

(b)

Fig. 5. Comparison of the bearing with compass compensation. (a) Rotation of the array; (b) Bearing estimation.

where

$$
\begin{gathered}
E=\left[\begin{array}{cc}
\sin \alpha_{1} & -\cos \alpha_{1} \\
\sin \alpha_{2} & -\cos \alpha_{2} \\
\vdots & \vdots \\
\sin \alpha_{N} & -\cos \alpha_{N}
\end{array}\right] \\
V=\left[\begin{array}{c}
{\left[\left(x_{s}-x_{1}\right) \cos \alpha_{1}+\left(y_{s}-y_{1}\right) \sin \alpha_{1}\right] \cdot \Delta \alpha_{1}} \\
{\left[\left(x_{s}-x_{2}\right) \cos \alpha_{2}+\left(y_{s}-y_{2}\right) \sin \alpha_{2}\right] \cdot \Delta \alpha_{2}} \\
\vdots \\
{\left[\left(x_{s}-x_{N}\right) \cos \alpha_{N}+\left(y_{s}-y_{N}\right) \sin \alpha_{N}\right] \cdot \Delta \alpha_{N}}
\end{array}\right], \\
D_{X}=\left[\begin{array}{c}
\Delta x \\
\Delta y
\end{array}\right] .
\end{gathered}
$$

This can be expressed as

$$
E D_{X}=V
$$

and the error of the estimator can be expressed as

$$
D_{X}=\left(E^{T} E\right)^{-1} E^{T} V
$$

From (22), we can see that the localisation results are influenced not only by the bearing error, but also by the position of each observing node, or geometry of the network. However, there are various kinds of geometry of the network, especially when the number of AWGs is large. Without loss of generality, we consider a case of IoUT where three AWGs are included.

Assume that the geometry of three nodes is an equilateral triangle and the distance between either two nodes is $6 \mathrm{~km}$. The area of $8 \mathrm{~km} \times 8 \mathrm{~km}$ is divided into grids of $100 \mathrm{~m} \times$ $100 \mathrm{~m}$. The localisation is estimated when the target locates in every grid under the bearing estimation error of $1^{\circ}, 2^{\circ}, 5^{\circ}$ and $10^{\circ}$. Then the localisation error distribution or Geometric Dilution Of Precision (GDOP) is computed as

$$
\operatorname{GDOP}(x, y)=\sqrt{\frac{1}{N} \sum_{n=1}^{N}\left(\left(\widehat{x}_{n}-x\right)^{2}+\left(\widehat{y}_{n}-y\right)^{2}\right)},
$$

where $N=200$ is the estimation number of each SNR, $\widehat{\alpha}_{n}$ is the $n$th bearing estimate, and $\alpha_{0}$ is the true bearing of the target. 
Fig. 6 shows the simulation results of GDOP under the aforementioned conditions. It can be found that the location error inside three nodes is much smaller than outside. When the length of baseline is determined, the localisation error increases with the bearing error. With such GDOP contour plots, the density or geometry of gliders can be calculated, with respect to the ability of bearing estimation, to efficiently construct the IoUT. In other words, precision of bearing estimation is limited by location goal and GDOP can be used to derive the requirements of each node and to optimize their geometry.

\section{SEA TRIAL EXPERIMENTS}

Here we use sea trial experimental data to verify the effectiveness of the multiple wave gliders.

\section{A. Experiment set-up}

To demonstrate the networking capability of AWG, an underwater acoustic positioning experiment was conducted in the Yellow Sea $\left(36^{\circ} 05^{\prime} N, 120^{\circ} 52^{\prime} E\right)$ near Qindao (see Fig. 7(a)) in the summer of 2019. The depth of the site is 32 meters and the bottom is relatively flat and silty as indicated from the chart. Many commercial ships passed by during the experiments since it is close to the shipping lane. The measured sound velocity is shown in Fig. 7(b), and the thermocline is about 10 meters depth.

Three wave gliders with each representing a node of the network, were deployed from the experiment ship sequentially in the geometry of an approximately equilateral triangle, with the side length of it about $2 \mathrm{~km}$. The ship acted two roles in the experiment: one is the 'target' radiating known sound signals to be localised and the other is as the data processing centre.

A source is deployed at a position of $15 \mathrm{~m}$ from the sea surface, and then transmitted continuous signal at frequency $311 \mathrm{~Hz}$. After the channel propagation, the acoustical signal is received by three acoustic units towed by three AWGs, at the depth of $17 \mathrm{~m}$ in order to avoid the influence of thermocline. Packaged with the data of depth and rotation of the acoustic units measured by the compass and pressure sensor respectively, then the data is transferred to the processing centre (ship) via VHF. The data is processed and the location of the source is derived and compared with the results measured by Global Positioning System (GPS) equipped on the ship.

During the experiment, we let the ship stay in the middle of three AWGs to achieve higher localisation precision and higher communication quality. However, because the distance between any pair of two wave gliders is relatively small, the precision of the AWG course control is hard to satisfy this requirement. Thus the shape of three AWGs quickly deviated from equilateral triangle. If more AWGs are deployed, better geometry can be selected to construct the network.

\section{B. Results and discussion}

In this experiment, the ability of IoUT was well demonstrated through acoustic signal acquisition, data transmission, and information extraction via data processing.

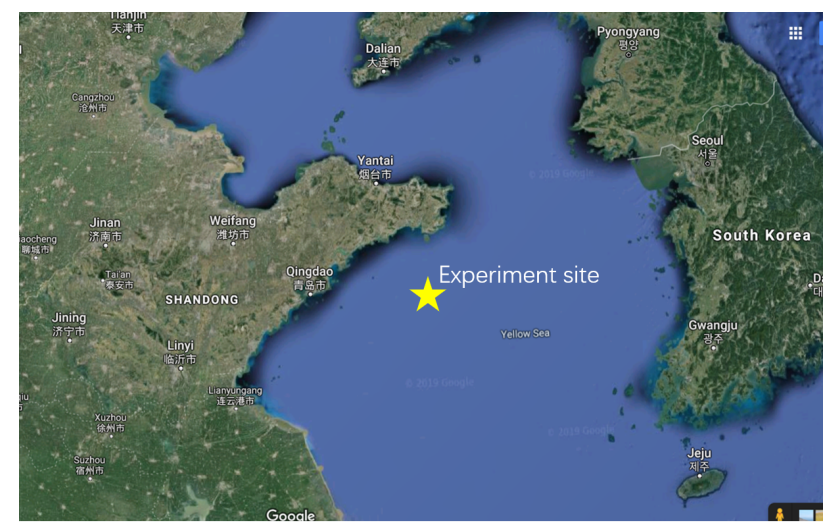

(a)

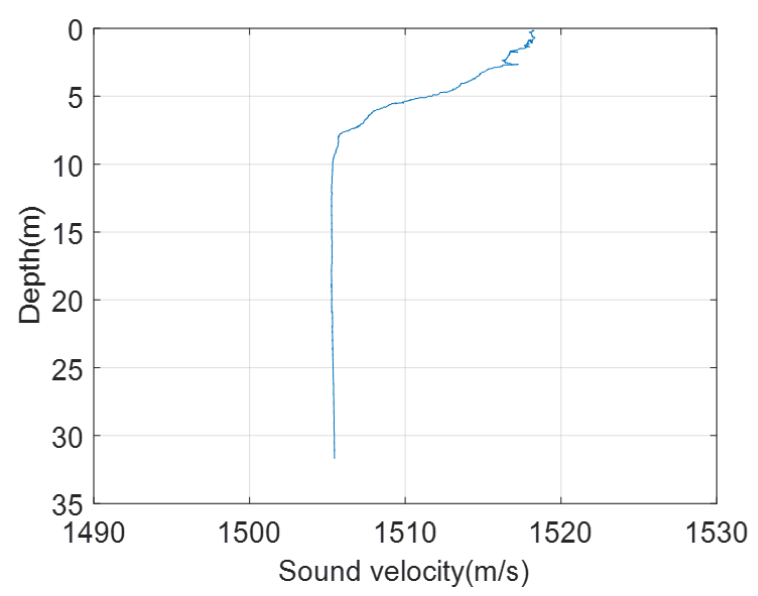

(b)

Fig. 7. Illustration of the experiment. (a) set-up of the experiment; (b) sound velocity profile.

Fig. 8(a), (c) and (e) show the acoustic data recorded by the hydrophone array and signal samples observed by 3 wave gliders, with the corresponding spectrum shown in Fig. 8(b), (d) and (f). As indicated by these curves, the structures of the frequency can be provided to the potential users, e.g. intensities or spectrum levels of acoustic sources. The source frequency of $311 \mathrm{~Hz}$ is prominent in these frequency spectral curves. The bearing estimations of the targets of interest were derived by this demonstrated IoUT. Without generality, here we assume that the target radiated a sound of $311 \mathrm{~Hz}$ from our ship in the sea trial.

Fig. 9(b), (d) and (f) show the bearing estimates, representing the bearing history of the target with respect to three AWGs, respectively. As illustrated in section III, the bearing can not be computed directly since the AWG platform is surged and rotated during the observation. The rotation history of the acoustic units corresponding to each AWG node are represented by the curves in Fig. 9(a), (c) and (e). The observation time lasted for one hour, and all three acoustic units continued rotating during this period under the effect of the flow. The rotating period is about 0.5 to $1 \mathrm{~s}$, and the maximum difference is $80^{\circ}$. With this rotation historical data, 


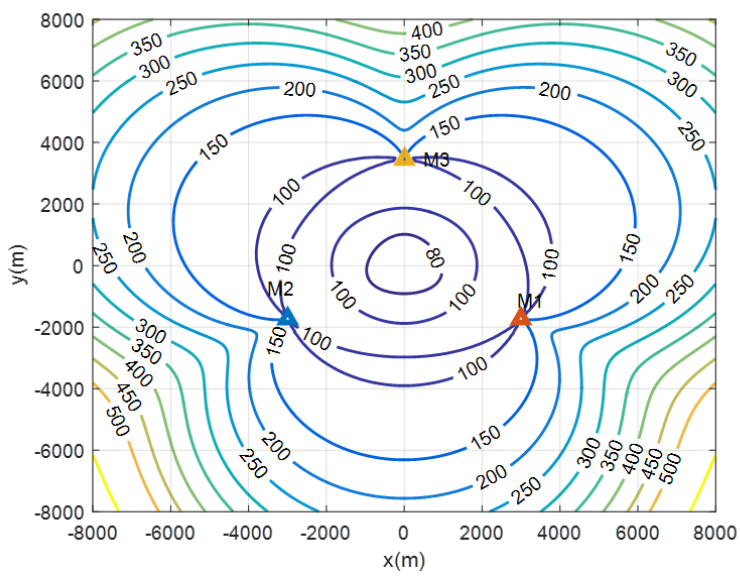

(a)

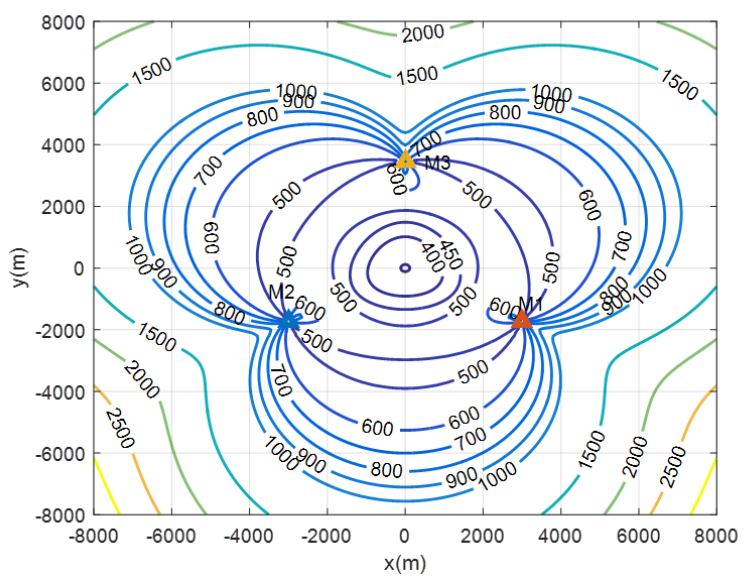

(c)

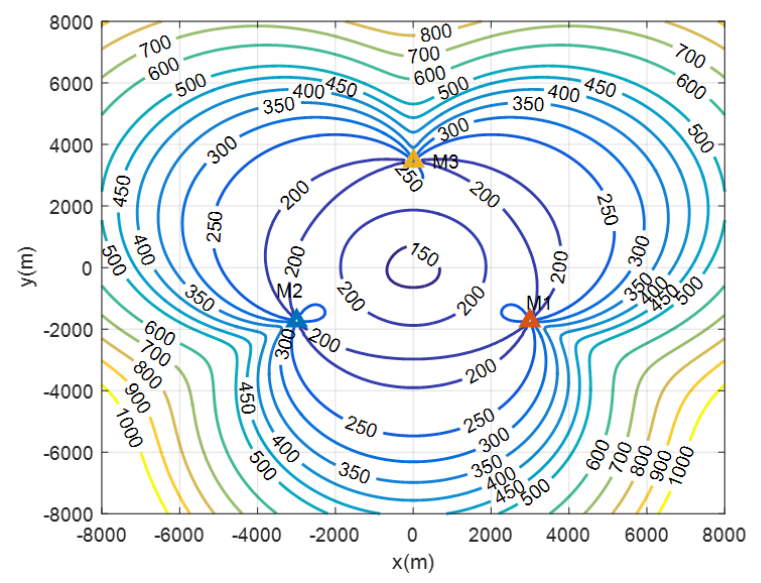

(b)

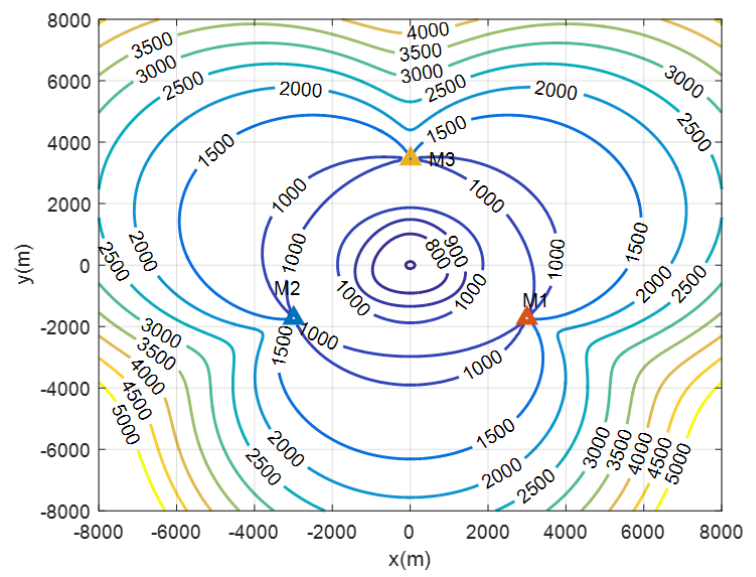

(d)

Fig. 6. GDOP of the localisation with bearing estimation. The numbers on the contour represent localisation error in meters in corresponding point. The triangle in the figure indicates three AWG nodes: (a) with bearing estimation error of $1^{\circ}$; (b) with bearing estimation error of $2^{\circ}$; (c) with bearing estimation error of $5^{\circ}$; (d) with bearing estimation error of $10^{\circ}$.

we conclude that the bearing estimation is unable to achieve good performance until the rotation is corrected properly.

Fig. 9(b), (d) and (f) show the results of rotationcompensated-bearing-estimation of three AWGs during the observation, corresponding to AWG1, AWG2 and AWG3. In each sub-figure, there are three curves, where the green solid curve is the true bearing of the source with respect to each AWG computed from the recorded GPS data. The blue curve marked with squares $\square$ is the bearing estimation of $311 \mathrm{~Hz}$ signal with direct compensation, and the green curve marked with arrows $\triangleright$ is the bearing of $311 \mathrm{~Hz}$ estimation with compound compensation method. The length of the signal for each estimate is $60 \mathrm{~s}$. Compared with the reference bearing, both bearing of acoustic unit with direct compensation and precise compensation fluctuates around the real value. The variance of the bearing estimation with compound compensation is about $1.5^{\circ}, 3^{\circ}$ and $4.4^{\circ}$, while variance of the bearing estimation is $10^{\circ}, 6.5^{\circ}$ and $11.4^{\circ}$. This is due to the rotation of the acoustic unit has been compensated every second for compound compensation method.

Target localisation is computed from bearing estimation of three AWGs. Fig. 10 shows the localisation results of a moving source using the acoustical bearing estimates of three AWGs. Tracks of three wave gliders, e.g. AWG1, AWG2 and AWG3, are illustrated in the figure, indicating that the moving directions are similar while the speeds are different. True course of the source was measured by the GPS and are shown as green line while the estimated course computed from the bearing estimation of three AWGs are shown as blue square $\square$. Fig. 10(b) shows the estimation error computed using (24). The errors vary from $10 \mathrm{~m}$ to $500 \mathrm{~m}$ whereas the distance between AWGs is about $5 \mathrm{~km}$. The results is consistent with the simulation results shown in Fig. 6.

\section{CONCLUSIONS}

In this paper, we proposed an architecture of IoUT with multiple AWGs as nodes for 'Smart Oceans'. We presented a compound compensation method of bearing estimation for a single AWG node under rotation of acoustic unit. Algorithm of localisation with bearings obtained by each nodes is also given, which is the core algorithm in the processing centre, 


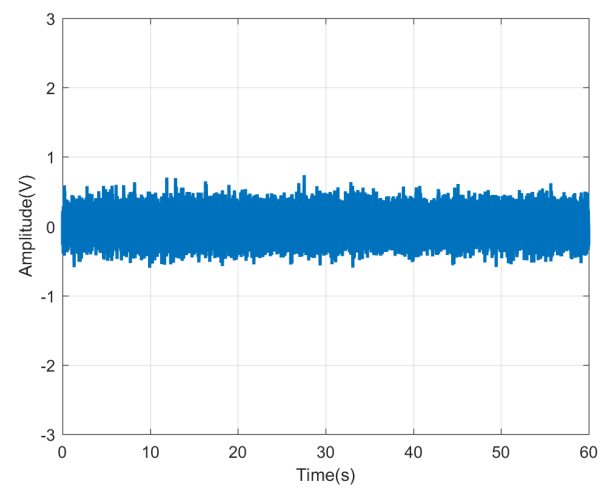

(a)

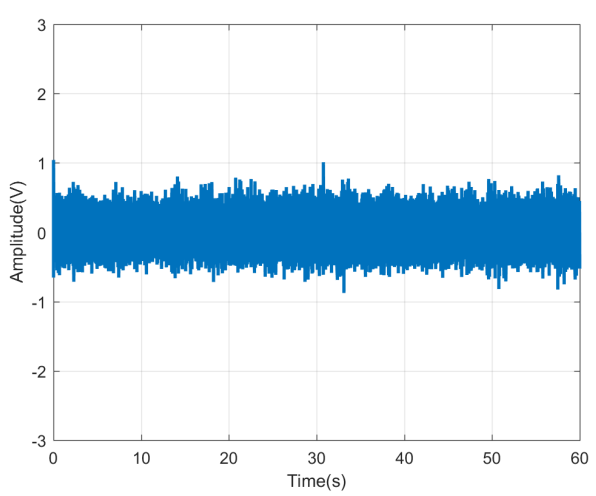

(c)

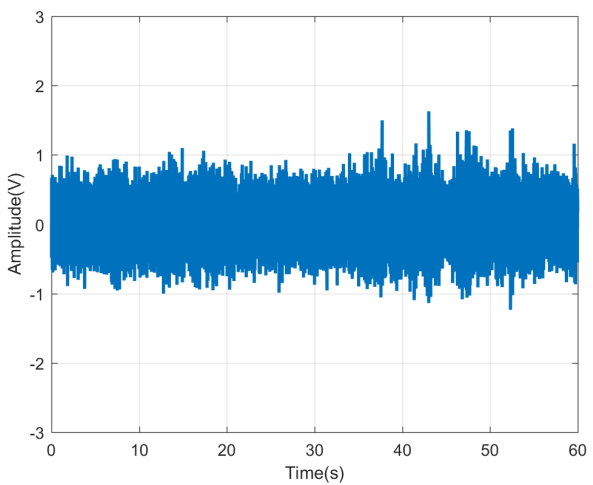

(e)

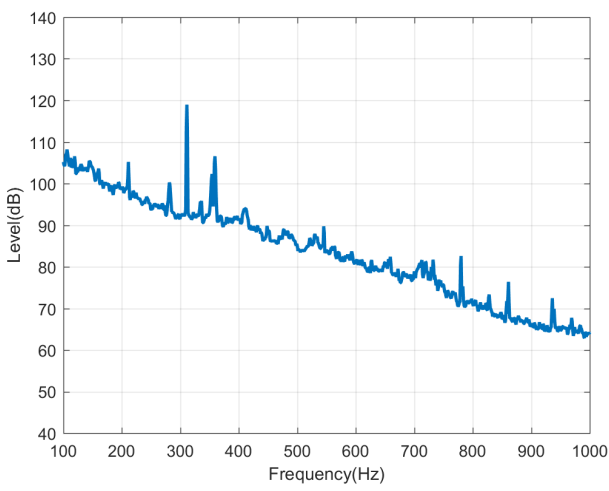

(b)

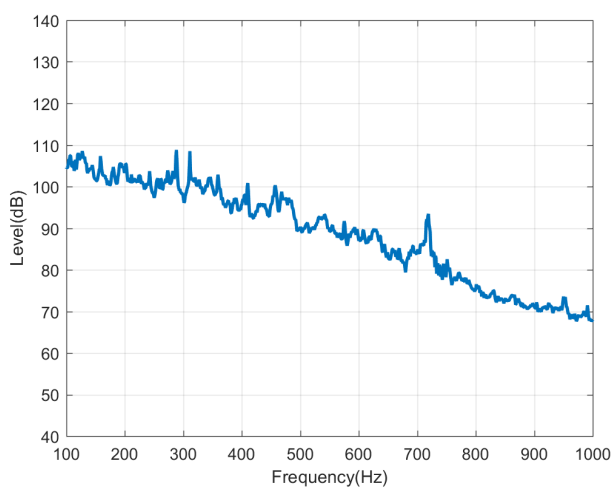

(d)

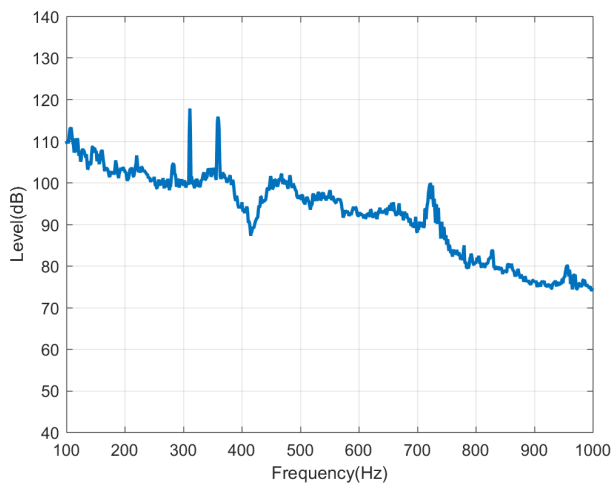

(f)

Fig. 8. Observed signal in time-domain and frequency domain. (a) Time-domain signal sample observed by AWG1; (b) Spectra observed by AWG1; (c) Time-domain signal sample observed by AWG2; (d) Spectra observed by AWG2; (e) Time-domain signal sample observed by AWG3; (f) Spectra observed by AWG3.

imposing the requirements of each node. The proposed methods have been validated by numerical simulation and sea trial experimental data. The results demonstrated that the Acoustic Wave Glider is suitable for long-term ocean observation and it can be extended to the global ocean in the development of Internet of Underwater Things.

\section{ACKNOWLEDGMENT}

The authors would like to thank Prof. Xiujun Sun for the provision of wave glider to conduct the sea trial. The work of this paper is supported by China NSFC (51609052, 61601134,
61871145) and National Natural Science Foundation of Heilongjiang (YQ2019D003).

\section{REFERENCES}

[1] K. Ashton et al., "That internet of things thing," RFID journal, vol. 22 , no. 7, pp. 97-114, 2009.

[2] A. Zanella, N. Bui, A. Castellani, L. Vangelista, and M. Zorzi, "Internet of things for smart cities," IEEE Internet of Things journal, vol. 1, no. 1 , pp. 22-32, 2014.

[3] L. Atzori, A. Iera, and G. Morabito, "The internet of things: A survey," Computer networks, vol. 54, no. 15, pp. 2787-2805, 2010.

[4] J. Yao, M. Jin, Q. Guo, Y. Li, and J. Xi, "Effective Energy Detection for IoT Systems against Noise Uncertainty at Low SNR," IEEE Internet of Things Journal, vol. 6, pp. 6165-6176, 2019. 


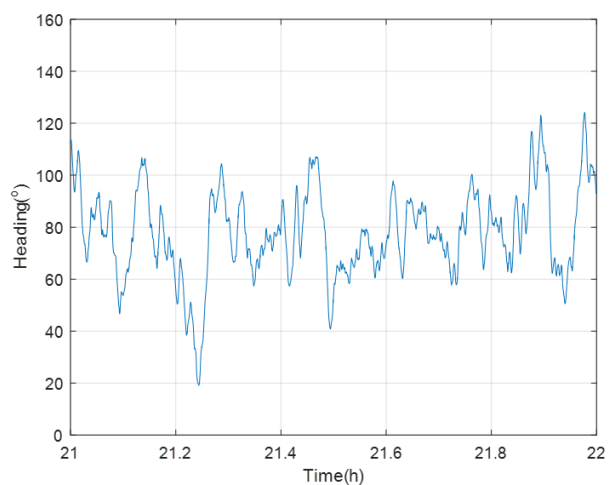

(a)

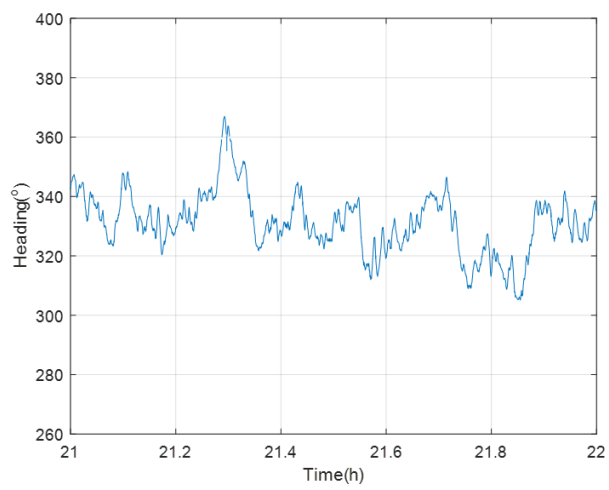

(c)

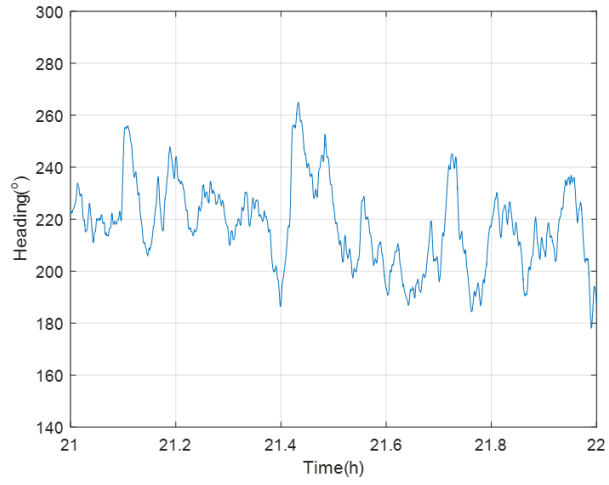

(e)

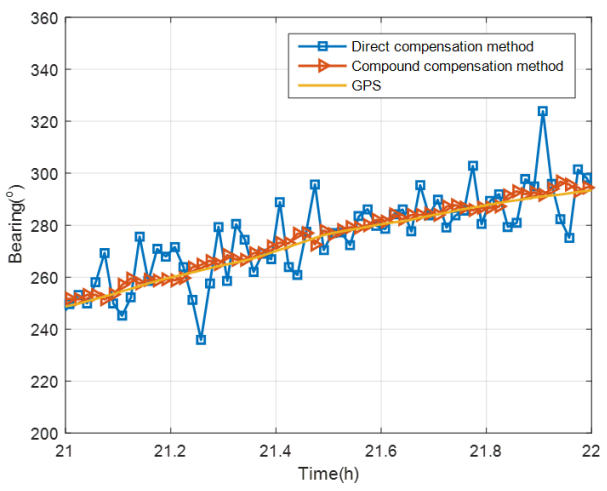

(b)

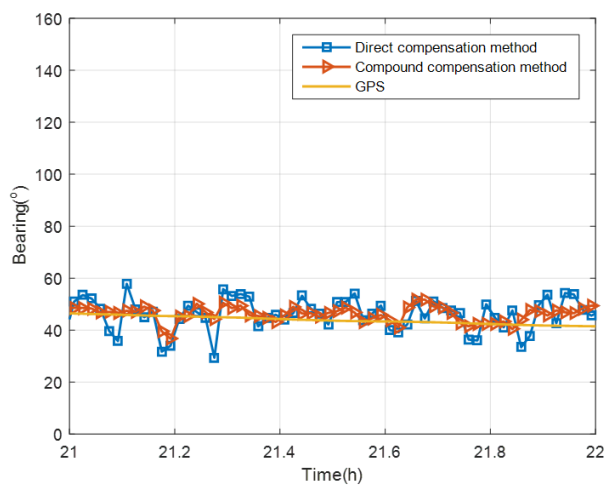

(d)

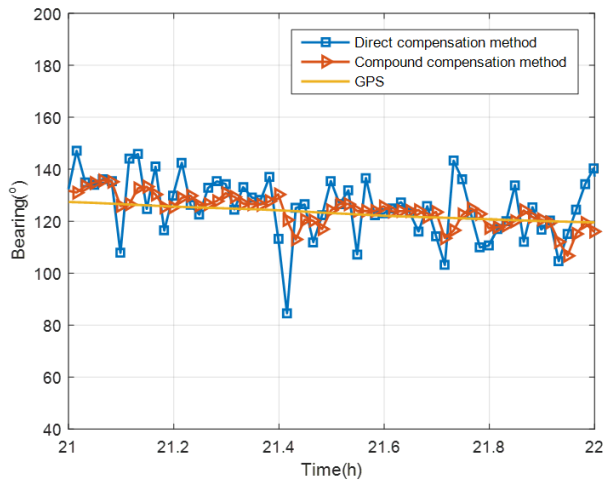

(f)

Fig. 9. Bearing estimation with each AWG node. (a) Rotation history of AWG1; (b) Bearing estimation with AWG1; (c) Rotation history of AWG2; (d) Bearing estimation with AWG2; (e) Rotation history of AWG3; (f) Bearing estimation with AWG3.

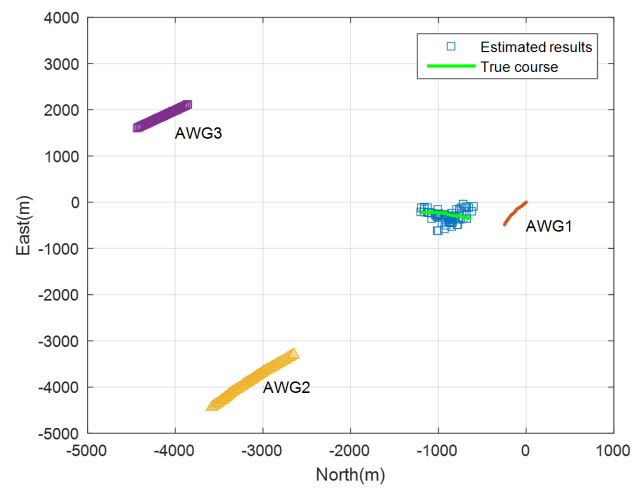

(a)

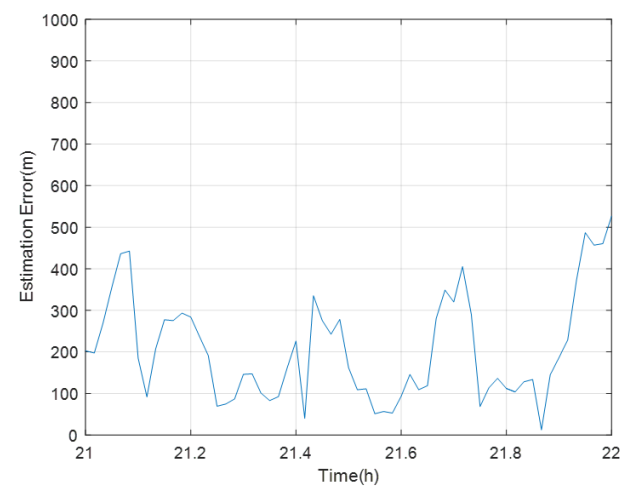

(b)

Fig. 10. Localisation of a moving source with bearing estimations from three AWGs. (a) results of localisation; (b) error history of localisation. 
[5] X.-C. Gao, J.-K. Zhang, H. Chen, Z. Dong, and B. Vucetic, "EnergyEfficient and Low-Latency Massive SIMO using Noncoherent ML Detection for Industrial IoT Communications," IEEE Internet of Things Journal, vol. 6, pp. 6247-6261, 2019.

[6] J. H. Nord, A. Koohang, and J. Paliszkiewicz, "The Internet of Things: Review and theoretical framework," Expert Systems with Applications, vol. 133, pp. 97-108, 2019.

[7] M. Aly, F. Khomh, M. Haoues, A. Quintero, and S. Yacout, "Enforcing security in internet of things frameworks: A systematic literature review," Internet of Things, vol. 6, pp. 1-24, 2019.

[8] S. Bhardwaj and A. Kole, "Review and study of internet of things: It's the future," in 2016 International Conference on Intelligent Control Power and Instrumentation (ICICPI). IEEE, 2016, pp. 47-50.

[9] J. A. Stankovic, "Research directions for the internet of things," IEEE Internet of Things Journal, vol. 1, no. 1, pp. 3-9, 2014.

[10] S. Chen, H. Xu, D. Liu, B. Hu, and H. Wang, "A vision of IoT: Applications, challenges, and opportunities with china perspective," IEEE Internet of Things journal, vol. 1, no. 4, pp. 349-359, 2014.

[11] M. A. Feki, F. Kawsar, M. Boussard, and L. Trappeniers, "The internet of things: the next technological revolution," Computer, no. 2, pp. 24 25, 2013.

[12] N. E. Cater, "Smart ocean Sensors Web Enabled ocean sensors for aquaculture," in OCEANS 2008. IEEE, 2008, pp. 1-9.

[13] N. E. Cater, P. Eng, and T. O'Reilly, "Promoting interoperable ocean sensors the smart ocean sensors consortium," in OCEANS 2009. IEEE, 2009, pp. 1-6.

[14] D. M. Toma, T. O’Reilly, J. del Rio, K. Headley, A. Manuel, A. Bröring, and D. Edgington, "Smart sensors for interoperable smart ocean environment," in OCEANS 2011 IEEE-Spain. IEEE, 2011, pp. 1-4.

[15] M. C. Domingo, "An overview of the internet of underwater things," Journal of Network and Computer Applications, vol. 35, no. 6, pp. 18791890, 2012.

[16] J. Kamruzzaman, G. Wang, G. Karmakar, I. Ahmad, and M. Z. A Bhuiyan, "Acoustic sensor networks in the Internet of Things applications," 2018.

[17] J. Yang, C. Wang, Q. Zhao, B. Jiang, Z. Lv, and A. K. Sangaiah, "Marine surveying and mapping system based on Cloud Computing and Internet of Things," Future Generation Computer Systems, vol. 85, pp. 39-50, 2018.

[18] N. Wright and H. Chan, "Low-cost Internet of Things ocean observation," in OCEANS 2016 MTS/IEEE Monterey. IEEE, 2016, pp. 1-5.

[19] Q. Wang, J. Li, Q. Qi, P. Zhou, and D. O. Wu, "A Game Theoretic Routing Protocol for 3D Underwater Acoustic Sensor Networks," IEEE Internet of Things Journal, 2020.

[20] E. Weippl, Internet of Things Security: Fundamentals, Techniques and Applications. River Publishers, 2018.

[21] J. Li and Y. V. Zakharov, "Efficient use of space-time clustering for underwater acoustic communications," IEEE Journal of Oceanic Engineering, vol. 43, no. 1, pp. 173-183, 2017.

[22] J. Li, Y. V. Zakharov, and B. Henson, "Multibranch autocorrelation method for Doppler estimation in underwater acoustic channels," IEEE Journal of oceanic engineering, vol. 43, no. 4, pp. 1099-1113, 2017.

[23] J. Li, Y. Bai, Y. Zhang, F. Qu, W. Yan, and J. Wang, "Cross power spectral density based beamforming for underwater acoustic communications," Ocean Engineering, vol. 1, no. 1, pp. 1-12, 2020.

[24] X. Zhuo, F. Qu, H. Yang, Y. Wei, Y. Wu, and J. Li, "Delay and queue aware adaptive scheduling-based MAC protocol for underwater acoustic sensor networks," IEEE Access, vol. 7, pp. 56263-56275, 2019.

[25] C.-C. Teng, S. Cucullu, S. McArthur, C. Kohler, B. Burnett, and L. Bernard, "Buoy Vandalism Experienced by NOAA National Data Buoy Center," in OCEANS 2009. IEEE, 2009, pp. 1-8.

[26] S. C. Riser, H. J. Freeland, D. Roemmich, S. Wijffels, A. Troisi, M. Belbéoch, D. Gilbert, J. Xu, S. Pouliquen, A. Thresher et al., "Fifteen years of ocean observations with the global Argo array," Nature Climate Change, vol. 6, no. 2, pp. 145-153, 2016.

[27] Z. Liu, X. Wu, J. Xu, H. Li, S. Lu, C. Sun, and M. Cao, "Fifteen years of ocean observations with China Argo," Advances in Earth Science, vol. 31, no. 5, pp. 445-460, 2016.

[28] R. L. Crout, D. T. Conlee, and L. J. Bernard, "National Data Buoy Center (NDBC) National Backbone Contributions to the Integrated Ocean Observation System (IOOS)," in OCEANS 2006, Sep. 2006, pp. $1-3$.

[29] D. C. Petraitis and S. M. DiNapoli, "Comparison of the NDBC 2.1Meter SCOOP Buoy to the Operational 3-Meter Buoy," in OCEANS 2018 MTS/IEEE Charleston. IEEE, 2018, pp. 1-7.
[30] B. Taft, M. Burdette, R. Riley, B. Hansen, W. Wells, D. Maxwell, and T. Mettlach, "Development of an NDBC standard buoy," in OCEANS 2009. IEEE, 2009, pp. 1-10.

[31] R. Riley and R. Bouchard, "NDBC wave measurement initiatives," in OCEANS 2015-MTS/IEEE Washington. IEEE, 2015, pp. 1-6.

[32] W. He, Z. Li, R. Malekian, X. Liu, and Z. Duan, "An internet of things approach for extracting featured data using AIS database: An application based on the viewpoint of connected ships," Symmetry, vol. 9, no. 9, p. 186, 2017.

[33] T. Ho, M. Hagaseth, A. Rialland, J. rnulf, r. Rdseth, R. Criado, and G. Ziaragkas, "Internet of Things at Sea: Using AIS and VHF over Satellite in Remote Areas," in Proceedings of 7th Transport Research Arena TRA 2018, April 16-19, 2018, Vienna, Austria, 04 2018, pp. 1-10.

[34] M. P. Meredith, O. Schofield, L. Newman, E. Urban, and M. Sparrow, "The vision for a southern ocean observing system," Current Opinion in Environmental Sustainability, vol. 5, no. 3-4, pp. 306-313, 2013.

[35] M. Susan Lozier, S. Bacon, A. S. Bower, S. A. Cunningham, M. Femke de Jong, L. De Steur, B. deYoung, J. Fischer, S. F. Gary, B. J. Greenan et al., "Overturning in the Subpolar North Atlantic Program: A new international ocean observing system," Bulletin of the American Meteorological Society, vol. 98, no. 4, pp. 737-752, 2017.

[36] P. Oke and P. Sakov, "Assessing the footprint of a regional ocean observing system," Journal of Marine Systems, vol. 105, pp. 30-51, 2012.

[37] D. Henderson, "NWS Marine Observation Network and the Integrated Sustained Ocean Observing System (IOOS)," in OCEANS'02 MTS/IEEE, vol. 3. IEEE, 2002, pp. 1652-1658.

[38] C. R. Barnes and N. C. Team, "Building the world's first regional cabled ocean observatory (NEPTUNE): realities, challenges and opportunities," in OCEANS. IEEE, 2007, pp. 1-8.

[39] D. W. Wallace, B. de Young, S. Iverson, J. LaRoche, F. Whoriskey, M. Lewis, P. Archambault, F. Davidson, D. Gilbert, B. Greenan et al., "A Canadian contribution to an integrated Atlantic ocean observing system (IAOOS)," in Oceans-St. John's. IEEE, 2014, pp. 1-10.

[40] C. Barnes, M. Best, B. Bornhold, S. Juniper, B. Pirenne, and P. Phibbs, "The NEPTUNE Project-a cabled ocean observatory in the NE Pacific: Overview, challenges and scientific objectives for the installation and operation of Stage I in Canadian waters," in 2007 Symposium on Underwater Technology and Workshop on Scientific Use of Submarine Cables and Related Technologies. IEEE, 2007, pp. 308-313.

[41] C. R. Barnes, M. M. Best, F. R. Johnson, L. Pautet, and B. Pirenne, "Challenges, benefits, and opportunities in installing and operating cabled ocean observatories: Perspectives from NEPTUNE Canada," IEEE Journal of Oceanic Engineering, vol. 38, no. 1, pp. 144-157, 2012.

[42] K. Foo, P. Atkins, T. Collins, S. Pointer, and C. Tiltman, "Sea trials of an underwater, ad hoc, acoustic network with stationary assets," IET radar, sonar \& navigation, vol. 4, no. 1, pp. 2-16, 2010.

[43] H. Lu, D. Wang, Y. Li, J. Li, X. Li, H. Kim, S. Serikawa, and I. Humar, "CONet: A cognitive ocean network," IEEE Wireless Communications, vol. 26, no. 3, pp. 90-96, 2019.

[44] M. Grund, L. Freitag, J. Preisig, and K. Ball, "The PLUSNet underwater communications system: acoustic telemetry for undersea surveillance," in OCEANS 2006. IEEE, 2006, pp. 1-5.

[45] J. Xu, P. Lermusiaux, P. Haley, W. Leslie, and O. Logutov, "Spatial and temporal variations in acoustic propagation in Dabob Bay during PLUSNet'07 Exercise," Journal of the Acoustical Society of America, vol. 123 , no. 5, p. 3894, 2008

[46] P. N. Mikhalevsky, H. Sagen, P. F. Worcester, A. B. Baggeroer, J. Orcutt, S. E. Moore, C. M. Lee, K. J. Vigness-Raposa, L. Freitag, M. Arrott et al., "Multipurpose acoustic networks in the integrated Arctic Ocean observing system," Arctic, pp. 11-27, 2015.

[47] T. Daniel, J. Manley, and N. Trenaman, "The Wave Glider: enabling a new approach to persistent ocean observation and research," Ocean Dynamics, vol. 61, no. 10, pp. 1509-1520, 2011.

[48] S. Frolov, J. Bellingham, W. Anderson, and G. Hine, "Wave GliderA platform for persistent monitoring of algal blooms," in OCEANS'11 MTS/IEEE KONA. IEEE, 2011, pp. 1-5.

[49] S. Wiggins, J. Manley, E. Brager, and B. Woolhiser, "Monitoring marine mammal acoustics using wave glider," in OCEANS 2010 MTS/IEEE SEATTLE. IEEE, 2010, pp. 1-4.

[50] J. Manley and S. Willcox, "The wave glider: A new concept for deploying ocean instrumentation," IEEE instrumentation \& measurement magazine, vol. 13, no. 6, pp. 8-13, 2010.

[51] M. Cimino, M. Cassen, S. Merrifield, and E. Terrill, "Detection efficiency of acoustic biotelemetry sensors on Wave Gliders," Animal Biotelemetry, vol. 6, no. 1, pp. 1-14, 2018. 
[52] D. Meyer, "Glider technology for ocean observations: a review," Ocean Sci. Discuss, pp. 1-26, 2016.

[53] B. Bingham, N. Kraus, B. Howe, L. Freitag, K. Ball, P. Koski, and E. Gallimore, "Passive and active acoustics using an autonomous wave glider," Journal of field robotics, vol. 29, no. 6, pp. 911-923, 2012.

[54] L. Wang, Y. Li, Y. Liao, K. Pan, and W. Zhang, "Course control of unmanned wave glider with heading information fusion," IEEE Transactions on Industrial Electronics, vol. 66, no. 10, pp. 7997-8007, 2018.

[55] M. Weyrich and C. Ebert, "Reference architectures for the internet of things," IEEE Software, vol. 33, no. 1, pp. 112-116, 2015. 